\title{
Research Progress of Eutrophication Assessment Methods for Coastal Waters
}

\author{
Zhao Shilan, Sun Helin, Ding Li \\ National Marine Environmental Monitoring Center, Dalian, China
}

\section{Email address:}

slzhao@nmemc.org.cn (Zhao Shilan), hlsun@nmemc.org.cn (Sun Helin), lding@nmemc.org.cn (Ding Li)

\section{To cite this article:}

Zhao Shilan, Sun Helin, Ding Li. Research Progress of Eutrophication Assessment Methods for Coastal Waters. Science Discovery. Vol. 4, No. 5, 2016, pp. 342-346. doi: 10.11648/j.sd.20160405.25

Received: September 26, 2016; Accepted: October 17, 2016; Published: November 5, 2016

\begin{abstract}
Reasonable assessment of water eutrophication is an important means, by which we can understand the pollution of water body accurately. In this paper, different assessment methods of coastal waters eutrophication are reviewed, in the purpose of contributing to the coastal waters eutrophication and ecological environment restoration.
\end{abstract}

Keywords: Coastal Waters, Eutrophication, Assessment Methods

\section{近岸海域富营养化评价方法研究进展}

赵仕兰*, 孙禾琳, 丁丽

国家海洋环境监测中心, 大连, 中国

邮箱

slzhao@nmemc. org. cn（赵仕兰），hlsun@nmemc. org. cn（孙禾琳），1ding@nmemc. org.cn（丁丽）

摘要：合理对水体富营养化状况进行评价是准确把握水体污染程度的重要手段, 本文综述了当前近岸海域富营养化评 价的主要方法及其优缺点, 以期为近岸海域富营养化评价以及生态环境修复工作提供技术支持。

关键词: 近岸海域, 富营养化, 评价方法

\section{1. 引言}

富营养化是一种氮、磷等植物营养物质含量过多所引 起的水质污染现象。近年来, 世界上许多临海国家近海水 域富营养化现象加剧, 赤潮频发, 对海域环境造成了极大 的破坏。近海海水富营养化及赤潮的发生也有加剧的趋势, 对水产养殖业、渔业以及人民的身体健康构成了严重的威 胁。

近年来, 随着沿海地区经济的发展, 排入河口、海湾 等近岸海域的氮、磷等营养物质也随之增加, 导致海水富 营养化严重并诱发赤潮, 近岸海域生态环境已受到了严重 的威胁。海洋渔业和养殖业遭受巨大的损失。水体富营养
化已成为困扰世界各国的主要环境问题之一 [1-3]。近岸 海域富营养化状况评价, 不仅是监测近岸海域生态环境变 化的一种有效方法, 也可为海水养殖以及海岸带生态环境 修复提供重要科学依据。本文综述了当前近岸海域富营养 化评价的主要方法及其优缺点, 旨在为近岸海域富营养化 评价以及生态环境修复工作提供技术支持。

\section{2. 近岸海域富营养化评价方法}

许多研究者对富营养化评价进行了研究, 并提出了多 种富营养化评价模型 [4], 然而, 迄今为止, 国际上尚未 有一个统一的富营养化评价标准或模型。有关海水富营养 
化评价方法大部分是从淡水水体的富营养化评价中移植 过来的, 主要包括单因子评价法、综合指数评价法、潜在 富营养化评价法、模糊数学法以及新近发展起来的综合评 价法和神经网络评价法等。

\section{1 . 单因子评价法}

单因子评价法是较早运用的方法, 其主要依据为海水 水质标准, 评价模式为:

$$
P_{i}=\frac{C_{i}}{C_{i 0}}
$$
数;

式中: $P_{i}$ 一第 $\mathrm{i}$ 项因子的标准指数, 即单因子标准指

$C_{i}$ 一第 $\mathrm{i}$ 项因子的实测浓度;

$C_{i 0}$ 一第i项因子的评价标准值。

当标准指数值 $P_{i}$ 大于 1 , 表示第 $\mathrm{i}$ 评价因子超出了其 相应的评价标准, 即表明该因子已不能满足评价海域海洋 功能区的要求。

由于富营养化的复杂性, 单因子指数评价法无法准确 地说明评价海域水体的综合富营养化的水平, 因此一般较 少单独使用，多为与其他评价方法搭配使用。

\section{2. 综合指数评价法}

由于单一的物理、化学和生物学指标很难准确地表示 复杂的富营养化现象, 富营养化评价体系从单因子法过渡 到综合指数法。

1) 营养指数法

营养指数法是目前海洋环境领域使用最多的富营养 化评价方法, 该方法由日本的冈市友利 [5]于1972年提出, 计算方程为:

$$
E=\frac{C O D(\mathrm{mg} / \mathrm{L}) \times D I N(\mathrm{mg} / \mathrm{L}) \times D I P(\mathrm{mg} / \mathrm{L}) \times 10^{6}}{4500}
$$

其中, $E$ 为营养指数, 当 $E \geqslant 1$ 时表明水域已经呈现富 营养化的特征。4500为来源于特定海域中COD、DIN、DIP 三者富营养化单项阈值的乘积。不同的海区，三者的阈值 也不同。其阈值范围一般为DIN $0.2 \sim 0.3 \mathrm{mg} / \mathrm{L}$, DIP 0. 01 $0.02 \mathrm{mg} / \mathrm{L}, \mathrm{COD} 1 \sim 3 \mathrm{mg} / \mathrm{L}$ 。邹景忠等 [6]较早引入营养指 数法, 并结合单因子指数法, 对渤海湾富营养化状况进行 了初步评价。林长清 [7]依据1989 1993年大连近海水质 监测资料, 选用营养状态指数法对大连湾和市区南部沿海 的富营养化水平进行了评价, 认为大连近海海域水质质量 状况较差, 处于富营养化状态, 局部海域属过营养化类型。 覃秋荣等 [8] 和赖俊翔等 [9] 分别利用该法对广西北海市 和钦州湾近岸海域富营养化状况进行了评价, 并通过分析 E值的变化情况探讨了可能造成富营养化状况的原因。

2）营养状态质量法

营养状态质量指数法 (NQI) 也是目前使用较多的评 价方法, 其计算公式为:

$$
N Q I=\frac{C O D}{C O D_{s}}+\frac{T N}{T N_{s}}+\frac{T P}{T P_{s}}+\left(\frac{\text { Chl.a }}{\text { Chl. } a_{s}}\right)
$$

其中, CODs、TNs、TPs和Chl. as 分别为COD、TN、TP 和Ch1. $a$ 的标准值。 $\mathrm{NQI}>3$ 为富营养水平; $\mathrm{NQI}=2 \sim 3$ 为中营 养水平; $N Q I<2$ 为贫营养水平。丘耀文等 $[10]$ 在分析 2001 年冬季和 2002 年夏季海陵湾附近海域营养盐及其他常规 参数时空分布特征的基础上, 应用营养状态质量指数的方 法评价该海域的水体富营养化状况，并通过多元线性回归 的方法分析叶绿素a与水环境要素的相互关系。杨斌等 [11] 基于 2009 年 8 月对钦州湾海域的现场调查资料, 分析了 钦州湾表层海水中营养盐的分布特征及其成因, 并采用营 养状态质量指数NQI 法对该海域富营养化状况进行评价 分析, 认为整个海湾水质处于中度污染程度和富营养化状 态, 以无机氮为主要污染因子。褚帆等 [12]于 2013 年7 月 对天津近岸海域海水营养盐和叶绿素a 等水质因子进行 采样调查, 运用营养状态质量指数法和富营养化指数法对 该海域海水富营养化水平进行评价, 采用主成分分析法得 出海水富营养化的驱动因子, 取得较好评价效果。

\section{3. 模糊数学综合评价法}

模糊综合评判法是模糊数学中一种函数型指数法, 它 把污染物超标值、水质质量分级标准、污染物在总体污染 中的贡献等几个方面联系在一起, 形成一种评价函数, 它 包含的数学信息广泛, 避免了综合指数法不能真实反映水 体污染状况、模式分辨性及可比性差等缺点, 因此广泛应 用于水质综合评价中 [13-16]。

隶属度函数是模糊控制的应用基础, 能否正确地构造 隶属度函数是能否用好模糊控制的关键之一。使用隶属度 函数对水体质量进行多因子综合评价时, 由实测资料计算 出的权值, 取决于现实污染源, 能比较客观地反映污染的 实况隶属度法的评价结果不受实测因子数目多寡的影响, 也不受污染因子异同的限制，因此，不同区域环境之间、 同一环境的不同时期之间都可以此法进行环境质量的评 价, 是一种用于评价水体富营养化的实用方法 [17]。另外, 如果对环境制订了统一的质量分类标准, 由这些标准拟出 隶属函数编制计算机程序, 则可以进行规范化的质量评价, 使用计算机进行运算又可大大节省运算时间及提高结果 的准确性。杜虹等 [18]根据2001 年7 月 2002 年7 月拓林 湾生态调查数据, 运用模糊集理论中的权距离概念, 结合 隶属度的模糊评价方法, 以化学耗氧量、总无机氮、活性 磷酸盐和叶绿素a 为指标, 对粤东拓林湾和湾外水域的富 营养化状况进行了评价。王焕松等 [19]基于2007年夏季辽 东湾海域的水质监测资料, 以高镇酸盐指数、溶解无机氮、 磷酸盐和溶解氧为海水富营养化评价指标, 运用模糊综合 评价方法并对其中的评价等级确定方法加以改进, 评价了 辽东湾海域水体富营养化状况, 分析了水体富营养化的关 键因子和控制性因素。夏斌等 [20]参照国家海水水质标准 和海水的富营养化特点, 选取活性磷酸盐、溶解无机氮、 溶解氧、化学需氧量和叶绿素 $\mathrm{a}$ 为评价指标, 将富营养化 程度分为 3 个级别, 利用灰类白化权函数描述海水富营养 化的等级界限, 确定各指标在灰类中的聚类权及聚类系数, 
确定各聚类对象的等级, 建立了海水富营养化综合评价模 型, 并应用该模型评价了2009年胶州湾海域富营养化状况, 认为灰色聚类法评价的胶州湾水域的富营养化状态与真 实情况接近, 利用灰色聚类法评价海水富营养化是一种快 速、简便、客观的方法。

\section{4. 潜在性富营养化评价法}

郭卫东等 $[21]$ 根据中国近岸海域的富营养化普运受 营养盐限制的特征，提出了潜在性富营养化的概念，并在 此基拙上提出了一种新的富营养化分级标准及相应的评 价模式。这一评价模式是基于1958年Redfield[22]提出的 Redfield系数, 即水体中所有能被浮游植物吸收利用的 $\mathrm{N}$ 与 $P$ 的比值为 16 而建立的。由于浮游植物主要吸收N、P物 质中的DIN和DIP, 因此为了便于统计研究, 彭云辉等 [23] 提出此处的 N、P物质简化为DIN和DIP, 并以此对长江口浮 游植物进行现场培养实验, 认为当 $\mathrm{N} / \mathrm{P}$ 大于 30 时受磷限制, $\mathrm{N} / \mathrm{P}$ 小于 8 时, 受氮限制。隋琪等 [24]基于 2014 年春季和冬 季渤海水域营养盐数据, 运用潜在性富营养化评价模式对 渤海水域营养水平进行了评价。曲丽梅等 [25]根据2002 年 6 月 9 月之间 4 个航次的调查资料, 阐述了辽东湾海域氮 磷营养盐的时空变化特征, 并对氨氮、硝酸态氮和亚硝酸 态氮、磷酸盐和 $\mathrm{pH}$ 及盐度进行了相关分析, 对海域进行了 潜在性富营养化评价。李桂菊等[26]根据2011 年5 月对 渤海湾海域 20 个站位海水营养盐的调查结果, 分析该海区 海水营养盐的分布特征, 并进行了潜在性富营养化评价。 其营养盐浓度分布特征与潜在性富营养化评价结果基本 一致。

\section{5. 综合评价法 (OSPAR-COMPP)}

随着人们对近岸海域富营养化问题认识上的进步和 管理的需求, 以富营养化症状为主的第 2 代富营养化评价 体系已经成为当前国际上近岸海域富营养化评价的主流, 最为著名且正被广泛应用的第 2 代河口及近岸海域富营 养化评价模型, 有美国的 “国家河口富营养化评价” （NEEA/ASSETS） [27-28] 和欧盟的 “综合评价法” (OSPAR-COMPP) [29], 其中美国ASSETS方法只适用于河 口; 欧盟的 “综合评价法” 以区域专属的背景值（即未受 人类活动干扰时的状态参数值) 为评价参考标准, 应用范 围更为广泛。

综合评价法 (Comprehensive Procedure) 是由欧盟于 2001年提出并应用于所有欧盟国家之沿岸海域的富营养 化状况评价方法, 共分为 4 类评价因子及标准。

I 类: 营养盐过富程度 (致害因素)

(1) 河流和直排总氮 (TN) 、总磷 (TP) 通量: 输入量增加 和/或趋势增加 (较以前年份高出 $50 \%$ 以上);

(2) 冬季无机氮 (DIN) 和/或无机磷 (DIP) 浓度: 浓度增 加 (高出与盐度相关的和/或区域专属背景值的 $50 \%$ 以上);

(3) 冬季N/P比值:N/P比值增大 $(>25)$ 。

II 类：富营养化的直接效应 (生长期)

(1) 叶绿素 $\mathrm{a}$ 浓度最大值和平均值: 浓度增加 (高出区 域专属背景值 $50 \%$ 以上);
（2）区域专属浮游植物指示种: 水平增加 (和持续期延 长) ;

(3) 大型植物包括大型藻类 (区域专属) : 如: 从长期生 长种转变为短期生长种或有害种。

III类：富营养化的间接效应 (生长期)

（1）缺氧程度：含量降低 ( $<2 \mathrm{mg} / \mathrm{L}$ 为急性危害; 4 〜 5 $\mathrm{mg} / \mathrm{L}$ 为危害-缺乏; $5^{\sim} 6 \mathrm{mg} / \mathrm{L}$ 为不足);

(2) 底栖动物改变/死亡和鱼类死亡: 死亡 (与缺氧和/ 或有毒藻有关), 底栖动物生物量和种类组成的长期变化;

(3) 有机碳/有机物: 含量增加〔与类别 I 有关〕（适 用于沉积区)。

IV 类: 富营养化可能产生的其它效应

如藻类毒素DSP/PSP贻贝传染事件等。

根据评价结果, 可将沿岸海域营养化状况综合分级为 四类: 问题海域、潜在问题海域和无问题海域。

目前, 运用综合评价法进行近岸海域富营养化评价的 报道较少, 王保栋等 [30] 以压力一状态一响应模式为基本 框架, 选取富营养化压力指标、状态指标和响应指标为评 价指标, 构建了近岸海域富营养化综合评价法, 该方法用 于评价长江口海域富营养化状况时与美国的ASSETS评价 结果一致。吴迪等 [31]基于PSR（压力-状态-响应）指标 框架建立了一套适用于河口环境的第二代富营养化综合 评价体系, 并以双台子河口生态监控区为例进行了富营养 化综合评价。张庆林等 [32] 以辽东湾东南部的红沿河海域 为研究对象, 运用国内目前常用的富营养化评价 (NQI) 方 法与新一代综合评价 (欧盟OSPAR-COMPP) 方法对研究海域 富营养化程度进行了评价, 并探讨了 2 种富营养化评价方 法的利弊。

\section{6. 人工神经网络评价法}

人工神经网络 (Artificial Neural Network) 是以大 脑的生理研究成果为基础, 模拟大脑的某些机理与机制进 行信息处理的一种数学模型 [33], 因其具有自学习、自组 织、较好的容错性和优良的非线性逼进能力等优点, 近年 来被许多研究学者应用于湖泊等陆地水域富营养化评价 中 [34-36], 其中多以采用误差逆传播的网络模型 (BP网 络) 来进行结果预测与评价。BP算法是Rumelhart于 1986 年提出的具有输入层、1 个或多个隐含层和输出层结构的 向前多层神经网络, 网络内同层各神经元互不连接, 相邻 层的神经元通过权值连接, 经过学习能够把样本隐含的特 征和规则分布于神经网络的连接权上, 使得算法适用于多 层网络。该方法常用于湖泊与河流等水域的富营养化评价、 水质评价, 还被用于海面风速和叶绿素浓度反演、潮位和 海底多金属结核分布探测、渔业资源补充量预报、植被变 化图精度改善、评估陆地施肥造成的土壤侵蚀、气候变化 与生态学等方面。相较于其他神经网络, BP神经网络具有 运算速度快, 叠加性好等特点。

人工神经网络评价法在海洋环境领域的应用尚不多 见, 王冬云等 [37]运用多层前馈神经网络模型和 $\mathrm{B}-\mathrm{P}$ 算 法对某海域的水质富营养化水平进行了评价, 作者认为运 用人工神经网络评价海水的富营养化, 只要把观测数据提 
供给网络, 借助计算机就可获得评价结果, 方法计算简便、 快速且具有实用性。

此外, 新近引入的海水富营养化评价的方法还包括支 持向量机 [38-39]、主成分分析 [40]、集对分析法 [41]等。

\section{3. 结论与展望}

合理对水体富营养化进行评价是准确把握水体污染 程度的重要手段, 然而, 由于富营养化评价受多个评价因 子的影响, 其间存在非线性关系, 且各因子的贡献存在较 大差异, 因此上述评价方法各有其适用条件和局限性, 迄 今尚未有一种公认的评价方法。在应用过程中, 有必要结 合评价海域的实际状况, 综合分析水体富营养化的原因, 选取恰当的评价指标和方法, 或者选取多种评价方法进行 比对分析, 为水体富营养化评价提供理论依据。

\section{致谢}

本文为环境基准与风险评估国家重点实验室项目《基 于神经网络的河口近岸海域富营养化评价技术研究》的阶 段性成果之一。

\section{参考文献}

[1] Nixon S W. Coastal eutrophication: A definition social causes and future concerns [J]. Ophelia, 1995, 41:99-220.

[2] Paerl H W. Coastal eutrophication and harmful algal blooms:Importance of atmospheric deposition and groundwater as "new" nitrogen and other nutrient sources [J]. Limnology and oceanography, 1997, 42 (5) : 1154-1165.

[3] Van Bennekom, Wetsteijn F J. The winter distribution of nutrients in the Southern Bight of the North Sea (1961-1978) and in the estuaries of the Scheldt and the Rhine/Meuse, Netherlands[J]. Journal of sea research, 1990, 25:75-87.

[4] 劳期团. 环境管理实用技术方法 [M]. 北京: 中国环境科学出 版社, 1994。

[5] 冈市友利. 浅海的污染与赤潮的发生, 内湾赤潮的发生机制 [R]. 日本水产资源保护协会, 1972:58-76。

６］邹景忠, 董丽萍, 秦保平. 渤海湾富营养化和赤潮问题的初 步探讨 [J]. 海洋环境科学, 1983, 2(2) : 41-54。

[7] 林长清. 大连近海富营养化评价与探讨 [J]. 海洋环境科 学, 1994, 13(4):63-68。

[8] 覃秋荣, 龙晓红. 北海市近岸海域富营养化评价 [J]. 海洋环 境科学, 2000, $19(2): 43-45$ 。
[9] 赖俊翔, 柯珂, 姜发军, 等. 广西钦州湾及邻近海域营养盐特 征与富营养化评价 $[J]$. 海洋环境科学, 2013, 32 (6) : 860-866。

[10] 丘耀文, 朱良生, 徐梅春, 等. 海陵湾水环境要素特征 $[\mathrm{J}]$. 海 洋科学, 2006, 30 (4) : 20-24。

[11] 杨斌, 方怀义, 钟秋平, 等. 钦州湾夏季营养盐的分布特征 及富营养化评价 [J]. 海洋通报, 2012, 31 (6) : 640-645。

[12] 褚帆, 刘宪斌, 刘占广, 等. 天津近岸海域海水富营养化评价 及其主成分分析 $[J]$. 海洋通报, 2015, 34(1) : 107-112。

[13] 刘延美, 刘守江, 曾阳梅. 模糊数学在西昌扔海富营养化评 价中的应用 $[\mathrm{J}]$. 四川环境, 2011, 30 (2) :67-70。

[14] 张平, 黄钰铃, 陈媛媛, 等. 模糊数学在香溪河库湾富营养 化评价中的应用 $[\mathrm{J}]$. 环境科学与技 术, 2012, 35(6) : 173-179。

[15] 丁铭, 崔嘉宇. 灰色聚类法在太湖富营养化评价中的应用 [J]. 污染防治技术, 2015, 28 (4) :21-24。

[16] 庞博, 李玉霞, 童玲. 基于灰色聚类法和模糊综合法的水质 评价 $[J]$. 环境科学与技术, 2011, 34 (11) : 185-188。

[17] 王化泉, 赵丽云. 海洋环境质量评价探讨一模糊集理论的 应用 $[J]$. 热带海洋, 1985, 4(2) : 44一51。

[18] 杜虹, 黄长江, 陈善文, 等. 粤东柘林湾海域富营养化评价与 分析 [J].生态科学, 2003, 22 (1) : 13-17。

[19] 王焕松, 雷坤, 李子成, 等. 辽东湾海域水体富营养化的模 糊综合评价 [J]. 环境科学研究, 2010, 23 (4) : 413-419。

[20] 夏斌, 陈碧鹃, 辛福言, 等. 灰色聚类法在胶州湾富营养化评 价中的应用 [J]. 渔业科学进展, 2011, 32 (5) : 114-120。

[21] 郭卫东, 章小明, 杨逸萍, 等. 中国近岸海域潜在性富营养化 程度的评价 $[\mathrm{J}]$. 台湾海峡, 1998, 17 (1) : 64-70。

[22] Redfield A C. The biological control of chemical factors in the environment[J].Am. Sci., 1958, 46:561-600.

[23] 彭云辉, 孙丽华, 陈浩如, 等. 大亚湾海区营养盐的变化及富 营养化研究 [J]. 海洋通报, 2002, 21 (3) : 44-48。

[24] 隋琪, 夏斌, 谢寒冰, 等. 2014年春季和冬季渤海海水营养盐 时空变化特征及富营养化评价 [J]. 渔业科学进 展, 2016, , 37 (2) : 10-15。

[25] 曲丽梅, 姚德, 丛丕福. 辽东湾氮磷营养盐变化特征及潜在 性富营养评价 [J]. 环境科学, 2006, 27 (2) :263-267。

[26] 李桂菊, 马玉兰, 李伟, 等. 春季渤海湾营养盐分布及潜在性 富营养化评价 [J]. 天津科技大学学报, 2012, 27 (5) : 22-27。

[27] Bricker S B, Ferreira J G, Simas T. An integrated methodology gor assessment of estuarine trophic status [J]. Ecol. Moel1. , 2003, 169:39-60.

[28] Bricker S B, Clement C G, Pirhalla D E, et al. National Estuarine Eutrophication Assessment: Effect of Nutrient Enrichment in the Nations Estuaries [M]. NOAA-NOS Special Projects Office, 1999:71. 
[29] OSPAR. Draft Common Assessment Criteria and Application within the Comprehensive Procedure of the Common Procedure [A]. Proceedings of the Meeting of the Eutrophication Task Group(ETG), London, 9-11 0ctober 2001[C]. London: OSPAR Convention for the Protection of the Marine Environment of the Northeast Atlantic, 2001.

[30］王保栋, 孙霞, 韦钦胜, 等. 我国近岸海域富营养化评价新方 法及应用 $[J]$ 。海洋学报, 2012, 34(4) :61-66。

[31] 吴迪, 王菊英, 马德毅, 等. 基于PSR框架的典型河口富营养 化综合评价方法研究 [J]. 海洋技术, 2010, 29 (3) : 29-33。

[32] 张庆林, 张学雷, 王晓, 等. 辽东湾东南海域富营养化评价 $[J]$. 海岸工程, 2009, 28 (1) : 38-43。

[33] RICKER S B, FERREIRA J G, SIMAST. An integrated methodology for assessment of estuarine trophic status[J]. Ecological Modelling. 2003, 169:39-60.

[34] 梁宵, 殷福才, 孙世群, 等. 基于人工神经网络的巢湖富营养 化分时分区评价 [J]. 中国环境监测, 2007, 23 (3) :74-76。
[35］任黎, 董增川, 李少华. 人工神经网络模型在太湖富营养化 评价中的应用 $[\mathrm{J}]$. 河海大学学报 (自然科学 版), 2004, 32(2) : 147-150。

[36] 林高松, 黄晓英, 李娟. 人工神经网络在深圳市水库富营养 化 评价 中的应用 $[\mathrm{J}]$. 环境监测管理 与 技 术, 2010, 22 (1):59-63。

[37] 王冬云, 黄炎歆. 海水富营养化评价的人工神经网络方法 $[J]$. 河北建筑科技学院学报, 2001, 18(4):27-29。

[38] 司晴, 梁伟. 海水富营养化评价的回归支持向量机规范化模 型 $[J]$. 四川环境, 2015, 34 (1) : 44-47。

[39] 王洪礼, 王长江, 李胜朋. 基于支持向量机理论的海水水质 富营养化评价研究 [J]. 海洋技术, 2005, 24 (1) : 48-51。

[40] 周斌, 王悠, 王进河, 等. 山东半岛南部近岸海域富营养化状 况的多元评价研究 [J]. 海洋学报, 2010, 32 (2) : 128-138。

[41] 李凡修, 陈武. 海水水质富营养化评价的集对分析方法 [J]. 海洋环境科学, 2003, 22 (2) : 72-74。 